12 COMPARISON OF NORMAL SALINE, HYPERTONIC ALBUMIN AND HYPERTONIC ALBUMIN PLUS TERLIPRESSIN RESUSCITATION IN AN INFANT ANIMAL MODEL OF HYPOVOLEMIC SHOCK

doi:10.1136/archdischild-2012-302724.0012

1J Urbano, 1,2R González, 1,2MJ Solana, 1,3J López, 'M Botrán, 'A García, 1,3J LópezHerce. 'Paediatric Intensive Care Unit, Gregorio Marañón General University Hospital and Research Institute; ${ }^{2}$ Healthcare Research Fund; ${ }^{3}$ Maternal and Child Health and Development Research Network, Carlos III Healthcare Institute, Madrid, Spain

Background and aims To determine if in an infant animal model of hemorrhagic shock, hypertonic albumin plus single bolus of terlipressin, as opposed to isotonic crystalloid, would improve global hemodynamic and perfusion parameters. No previous experience in children or infant animal models has been reported.

Methods Prospective, randomized study in 30 two month-old piglets $(9.9 \pm 2 \mathrm{~kg})$. Following mechanical ventilation, hypovolemia was induced by controlled $30 \mathrm{ml} / \mathrm{kg}$ bleed. After $30^{\prime}$ pigs randomly received: Normal Saline (NS) $30 \mathrm{ml} / \mathrm{kg}, \mathrm{n}=10$, Albumin $5 \%$ plus Hypertonic $3 \%$ Saline (AHS) $15 \mathrm{ml} / \mathrm{kg}, \mathrm{n}=10$, or single bolus of terlipressin $20 \mu \mathrm{g} / \mathrm{Kg}$ iv plus AHS (TAHS) $15 \mathrm{ml} / \mathrm{kg}, \mathrm{n}=10$, over $30 \mathrm{~min}$. Heart rate (HR), mean arterial pressure (MAP), cardiac index (CI), brain tissue oxygenation by near infrared spectroscopy (bTOI), internal carotid artery flow (ICAF), arterial lactate and intramucosal gastric $\mathrm{pH}(\mathrm{pHi})$ were compared by ANOVA.

Results 30' after bleeding as well as 30', 60' and 90' after infusion no significant differences between groups were observed. However, 90' after infusion the TAHS group presented trends towards higher MAP (NS: 71 \pm 8 , AHS: 74 \pm 7 , TAHS: $82 \pm 7 \mathrm{mmHg}$ ); CI (NS: $3.2 \pm 0.3$, AHS: $3.8 \pm 0.3$, TAHS: $4.2 \pm 0.3 \mathrm{~L} / \mathrm{min} / \mathrm{m}^{2}$ ); lactate (NS: $1.7 \pm 1.7$, AHS: $0.8 \pm 1.4$, TASH: $3.6 \pm 1.4 \mathrm{mmol} / \mathrm{L}$ ); bTOI (NS: $42 \pm 5$, AHS: $45 \pm 4$, TASH: $48 \pm 6 \%$ ); and ICAF (NS: $41 \pm 4$, AHS: $42 \pm 4$, TASH: $48 \pm 3 \mathrm{~mL} /$ min); with no differences in HR (NS: $166 \pm 11$, AHS: $145 \pm 10$, TAHS: $159 \pm 9 \mathrm{bpm}$ ); and pHi (NS: 7.1 \pm 0.1 , AHS: 7.2 \pm 0.1 , TASH: 7.2 \pm 0.1 ).

Conclusion All fluids achieved similar hemodynamic and perfusion endpoints without a significant improvement secondary to the use of terlipressin.

\section{VALIDATION OF EXTRAVASCULAR LUNGWATER MEASUREMENT BY TRANSPULMONARY THERMODILUTION IN SEVERE PULMONARY EDEMA IN A NEWBORN ANIMAL MODEL}

doi:10.1136/archdischild-2012-302724.0013

${ }^{1} \mathrm{~A}$ Nusmeier, ${ }^{2} \mathrm{~S}$ Vrancken, ${ }^{2} \mathrm{WP}$ de Boode, ' JG Van der Hoeven, ${ }^{1} \mathrm{~J}$ Lemson. 'Intensive Care; ${ }^{2}$ Neonatology, Radboud University Nijmegen Medical Center, Nijmegen, The Netherlands

Introduction Extravascular lungwater (EVLW) can be measured at the bedside using the transpulmonary thermodilution method (TPTD), which quantifies the amount of pulmonary edema. This technique has never been validated in conditions of high indexed EVLW levels measured in infants and young children. We compared EVLW $_{\text {TPTD }}$ measurements with the transpulmonary double indicator dilution method (TPDD; ice-cold indocyanin green) and post mortem gravimetry.

Methods In eleven newborn lambs pulmonary edema was induced using a surfactant wash-out lavage ALI model. Serial EVLW measurements by TPTD and TPDD were performed at various levels of lung water and the final EVLW values were compared with the post mortem gravimetry results. Data were analyzed using correlation statistics (Spearman's coefficient of rank correlation (rho)).

Results A total of 25 simultaneous TPTD and TPDD measurements from ten lambs were analyzed with a median EVLWI $_{\text {TPDD }}$ of 24.0 (IOR 20.7) $\mathrm{ml} / \mathrm{kg}$. One lamb died before the measurements were performed. Correlation between EVLW $_{\text {TPTD }}$ and EVLW ${ }_{\text {TPDD }}$ was $\mathrm{r}=0.94$ (figure1; $\mathrm{p}<0.0001,95 \% \mathrm{CI}$ 0.87-0.97). Median EVLW ${ }_{\text {Gravimetry }}$ was 23.9 (IOR9.4) $\mathrm{ml} / \mathrm{kg}$. The correlation between the fina $\mathrm{EVLW}_{\text {TPTD }}$ and the EVLW Gravimetry $_{\text {was }} \mathrm{r}=0.93$ (figure2; $\mathrm{p}<0.0002$, 95\%CI 0.71-0.99).

Conclusions EVLW measurements by TPTD in severe pulmonary edema correlate well with the gold standards.

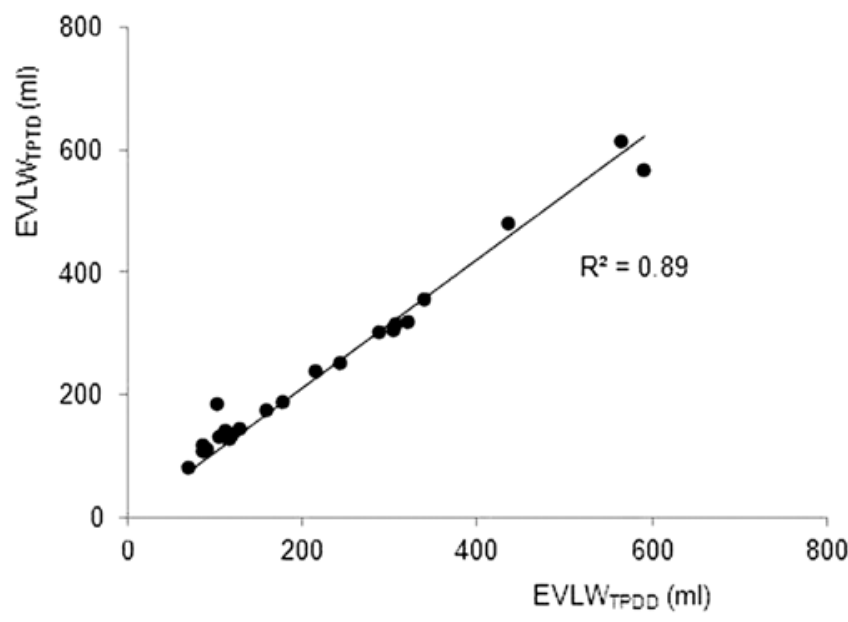

Abstract 13 Figure 1 Correlation EVLW-TPTD and EVLW-TPDD

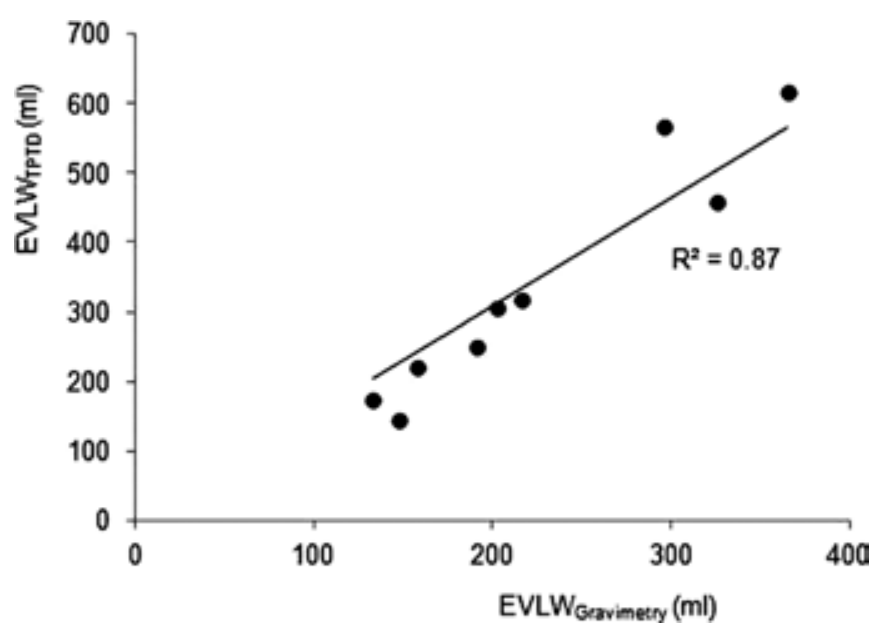

Abstract 13 Figure 2 Correlation EVLW-TPTD and EVLW-gravimetry

\begin{tabular}{ll}
\hline 14 & PREDICTION OF FLUID RESPONSIVENESS IN \\
MECHANICALLY VENTILATED CHILDREN USING \\
TRANSOESOPHAGEAL DOPPLER (TOD) AND \\
TRANSTHORACIC ECHOCARDIOGRAPHY (TTE) IN \\
ALGERIAN'S PICU
\end{tabular}

doi:10.1136/archdischild-2012-302724.0014

K El Halimi, MA Negadi, H Bouguetof, D Boumendil, ZC Mentouri. Pediatric Intensive Care Unit, Faculty of Medicine, Oran University, Oran, Algeria

Background and aims Circulatory failure treatment needs to assess blood volume status, in order to detect a hypovolemia requiring blood volume expansion. In this way, new dynamic echocardiographic and TOD parameters have recently been proposed in mechanically ventilated children, using the heart lung interactions, such as respiratory changes of aortic blood flow velocity, and inferior vena cava diameter. 